\title{
Endogenous Market Structure and the Cooperative Firm
}

\author{
Brent Hueth and GianCarlo Moschini
}

\section{Working Paper 14-WP 547}

May 2014

\author{
Center for Agricultural and Rural Development \\ lowa State University \\ Ames, lowa 50011-1070 \\ www.card.iastate.edu
}

Brent Hueth is Associate Professor, Agricultural and Applied Economics Director, University of Wisconsin-Madiso. E-mail: hueth@wisc.edu.

GianCarlo Moschini is Professor of Economic, lowa State University. E-mail:mischini@iastate.edu.

This publication is available online on the CARD website: www.card.iastate.edu. Permission is granted to reproduce this information with appropriate attribution to the author and the Center for Agricultural and Rural Development, lowa State University, Ames, lowa 50011-1070.

lowa State University does not discriminate on the basis of race, color, age, ethnicity, religion, national origin, pregnancy, sexual orientation, gender identity, genetic information, sex, marital status, disability, or status as a U.S. veteran. Inquiries can be directed to the Interim Assistant Director of Equal Opportunity and Compliance, 3280 Beardshear Hall, (515) 294-7612. 


\title{
Endogenous Market Structure and the Cooperative Firm
}

Brent Hueth ${ }^{\mathrm{a}}$ and GianCarlo Moschini ${ }^{\mathrm{b}}$

\begin{abstract}
When the threat of entry by followers includes cooperative firms, the maximum fixed cost that a profit maximizing leader can endure is endogenous. The aggressive strategy required for entry deterrence curtails the leader's expected profit and can discourage its initial entry. In such circumstances a cooperative firm may yet be viable, despite having a cost handicap and no firstmover advantage.
\end{abstract}

Keywords: cooperatives, endogenous entry, entry deterrence, nonconvexity.

JEL codes: L22, P13

a Department of Agricultural \& Applied Economics, University of Wisconsin-Madison, Madison, WI 53706-1503

b Department of Economics and Center for Agriculture and Rural Development, Iowa State University, Ames, IA 50011-1070 


\section{Introduction}

Industrial organization has long recognized that market structure is the result of rational entry decisions by firms vis-à-vis the profit opportunities present in a market. Mankiw and Whinston (1986) show that, with fixed set-up costs, the free entry equilibrium in a large class of oligopolistic models typically exhibits an excessively large number of active firms. An emerging literature has introduced the Stackelberg notion of leadership in this endogenous market structure (EMS) context, where one firm has the opportunity to make its entry decisions before the other firms - see Etro (2013) for a recent survey. A general insight from this framework is that a leader facing endogenous entry tends to behave more aggressively (relative to the situation when the set of followers is predetermined). In this context the leader is most interested in influencing the entry decision of the followers, rather than their production/price decision. Specific results depend on the nature of the model. But in general the excessive entry result disappears, as it is common to find that equilibrium entails entry deterrence, i.e., there is only one firm (the leader) in the market (Etro, 2008).

In this paper we extend the EMS framework by posing that the leader, in addition to being concerned about entry by other profit maximizing (PM) firms, also faces the threat of entry by coalitions of consumers (i.e., "cooperative firms"). In this context, the case of large fixed entry costs is of particular interest. For large enough fixed entry cost, even a firm unconstrained by the threat of subsequent entry cannot make positive profits. This situation represents one instance in which the excessive entry result noted earlier may not apply, i.e., equilibrium entry is of the "too few by one" kind (Mankiw and Whinston 1986): consumer surplus may be sufficient to cover all (variable and fixed) costs, yet no firm finds it profitable to enter (under the standard assumption that a monopolist does not capture the full social surplus generated by entry). In such a case a cooperative firm may feasibly produce, however, if its members bear a portion of fixed cost through a membership fee or other lump sum contribution.

More interesting is the fact that the prospect of entry by a cooperative firm affects the strategy of the leader. Extending Etro's (2008) framework, the leader must consider entry deterrence strategies not only with respect to other firms, but also with respect to the possible entry of cooperative firms. Entry deterrence of consumer coalitions by an incumbent monopolist was extensively analyzed by Sexton and Sexton (1987) and Innes and Sexton (1993). Deterrence of consumer coalitions calls for an even more aggressive behavior than that required to deter other PM firms. The implication of this observation for the EMS problem analyzed here is that, whereas the leader can succeed in securing the market as a monopolist by exploiting its first mover advantage, entry deterrence limits the profit that can be realized. This limits the range of fixed cost that can be borne by the leader, which in turn expands the region of parameters where the cooperative firm enters in response to the absence of a PM firm. 


\section{EMS and entry deterrence}

We consider the simplest possible framework to illustrate the result of interest. For all firms, the technology of production is represented by the cost function

$$
C(Q)=c Q+K
$$

where $c>0$ is the constant marginal production cost, and $K>0$ is the fixed setup cost that is required to enter the market. Following Etro (2008), the model is a three-stage game. In stage 1, the PM firm decides whether or not to enter after considering the prospect of competition by followers (other PM firms or coalitions of consumers). In stage 2, if the leader PM firm has entered, it will play the entry-deterrence strategy as needed. For some domain of $K$, it turns out that other firms do not enter, the consumer coalition does not form, and the leader operates as the only firm in equilibrium. In stage 3, if the leader PM firm has not entered, a consumer coalition may form, without having to face deterrence.

For the demand side of the model, for concreteness we assume that there are $N$ identical consumers with quasilinear preferences, such that the aggregate demand function is

$$
D(p)=a-p,
$$

with individual demand functions given by $D_{i}(p)=D(p) / N, i=1,2, \ldots, N$.

If the leader can behave as an unconstrained monopolist, given the assumed aggregate demand function, then it solves

$$
\max _{p}(a-p)(p-c)-K
$$

yielding the standard monopoly price $p^{m}=(a+c) / 2$ and production level $Q^{m}=(a-c) / 2$, provided $K$ is not too large. The monopolist earns positive profit as long as $K \leq K^{m}$ where $K^{m}$ is the maximum fixed cost that can be sustained by a monopolist unconstrained by the threat of entry:

(1) $\quad K^{m} \equiv \frac{(a-c)^{2}}{4}$

In Stackelberg competition for homogeneous goods where, upon entry, firms compete in quantities, the leader can deter entry of other PM firms by producing $Q_{L}=a-c-2 \sqrt{K}$, provided $K \leq((a-c) / 4)^{2} \equiv \bar{K}$ (Etro, 2008). The limit price of this equilibrium is 


$$
p_{L}=c+2 \sqrt{K}
$$

Remark 1. The need to deter entry of other PM firms does not affect the maximum level of fixed cost that the leader can bear (because $\bar{K}<K^{m}$ ).

\subsection{The cooperative firm}

Owing to their distinctive governance structure, cooperative firms behave differently than PM firms, but in ways that eschew a single modeling approach. The literature has emphasized various circumstances in which cooperatives might make production decisions that are more or less efficient than a PM firm (Hansmann 1994, 2013; Hart and Moore, 1996; Mikami, 2011). They are more responsive to the consumption needs of their members and thus pursue more efficient production plans, but they also have coordination and governance costs that a PM firm does not face. We follow Innes and Sexton (1993) and capture such governance costs unique to cooperative firms by a function $G(n)$ that is increasing and concave in the size $n \leq N$ of the cooperative. Effectively, therefore, a cooperative firm faces the higher fixed cost of entry $K+G(n)$. It is assumed that the objective of the cooperative is to maximize the consumer surplus of its members, net of all production and governance costs. Hence, the cooperative firm would produce the efficient amount $D(c)$, which is then allocated to members by marginal cost pricing $p^{c}=c$. Furthermore, if market conditions are such that a coalition of consumers is formed, then it is reasonable to focus on the case $n=N$ (i.e., the grand coalition) because $[K+G(n)] / n$ is decreasing in the cooperative size. In what follows, therefore, we simply write $G$ rather than $G(N)$ for the total governance cost of the cooperative.

The foregoing structure is the simplest representation of the cooperative firm that permits us to illustrate the main result of the paper. We note, however, that an analogous result can be obtained with more general representations of the cooperative decision problem, for example one which allows for consumer heterogeneity and where decision are made by majority voting, as in Hart and Moore (1996).

Given efficient production, the combined payoff of the cooperative firm is

(3) $\quad U=\frac{(a-c)^{2}}{2}-K-G$

Hence, the maximum fixed cost that the co-op firm can sustain and still be viable is 
(4) $\quad K^{c} \equiv \frac{(a-c)^{2}}{2}-G$.

\subsection{Deterrence of cooperative entry}

Deterrence of a consumer coalition by an incumbent monopolist who relies on a policy of uniform price offers was considered by Sexton and Sexton (1987). Innes and Sexton (1993) extend this analysis by allowing the incumbent firm to pursue a "divide-and-conquer" entry deterrence strategy, leading to a form of price discrimination. They fully articulate two formulations of such a strategy. Our approach here is consistent with their "model II," which maintains the appealing condition that consumers can evaluate their individual offers vis-à-vis the gains from various possible coalitions (which, inter alia, rationalizes the focus on the grand coalition invoked earlier). When all consumers have identical demands, as in our case, the entry-deterring monopolist does not price discriminate. Hence, to deter the cooperative formation the leader must commit to a price (or production plan) that grants to the grand coalition as much surplus as the latter could generate by itself if it integrated into production.

The total net surplus enjoyed by the grand coalition is given by (3). When consumers instead buy from the leader at any given price $p$, they get a total surplus $S(p)=(a-p)^{2} / 2$. Hence, the price $p_{D}$ that just deters the formation of a cooperative solves $S\left(p_{D}\right)=U$ yielding

$$
p_{D}=a-\sqrt{(a-c)^{2}-2(K+G)} .
$$

Remark 2. For sufficiently low governance cost, $p_{D}<p_{L}$. To deter the formation of a cooperative firm the incumbent may need to behave more aggressively than to deter other PM firms.

\section{Equilibrium entry}

In the first stage the would-be monopolist has to decide whether or not to enter the market. Let $\pi_{D}^{m}$ denote the ex post profit of the monopolist (that is, exclusive of its own fixed setup cost $K$ ).

First, note that deterrence can be achieved by the unconstrained monopoly price $p^{m}$ if

$$
\frac{(a-c)^{2}}{2}-K-G \leq \frac{\left(a-p^{m}\right)^{2}}{2} \rightarrow 3 \bar{u} \leq K+G
$$


where $\bar{u} \equiv(a-c)^{2} / 8$ is the consumer surplus at the monopoly price $p^{m}$. In this case entry is blockaded and the monopolist achieves its highest possible profit, which defines the maximum fixed cost that it can incur in stage 1 and still be viable, as identified in (1): $\left.\pi_{D}^{m}\right|_{p^{m}}=2 \bar{u} \equiv K^{m}$.

When $K+G<3 \bar{u}$, on the other hand, blockaded entry is not possible and the monopolist must use $p_{D}$ given in (5) to deter entry. The ex post profit of the monopolist $\pi_{D}^{m}=\left(p^{D}-c\right)\left(a-p^{D}\right)$ in this case depends on the fixed costs $K$ and $G$ that must be incurred by the cooperative:

$$
\pi_{D}^{m}(K, G)=2(\sqrt{4 \bar{u}[4 \bar{u}-(K+G)]}-4 \bar{u}+(K+G)) .
$$

The relevant regions of the parameters are illustrated in Figure 1. For a given $K$ this ex post profit is non-decreasing in the cooperative's coordination cost $G$. For $G \geq 3 \bar{u}-K$, entry is blockaded by the unconstrained uniform price $p^{m}$ and the leader reaches the maximum ex post profit: $\pi_{D}^{m}=2 \bar{u}$. But as the coordination cost decreases below $\bar{u}$, price concessions are necessary to deter the formation of a consumer coalition, meaning that $\pi_{D}^{m}(K, G)$ decreases in $G$ for a given $K$. Hence, the maximum level of fixed cost that the would-be monopolist can endure in stage 1 also decreases. Specifically, the region of parameters where the monopolist will make nonnegative profit (from a stage 1 perspective, meaning $\pi_{D}^{m} \geq K$ ) is represented by the dotted-shaded area in Figure 1. To the East and South of the boundary of this region, the PM firm does not enter.

The horizontal-line-shaded area in Figure 1 illustrates the parameter space $(K, G)$ where the PM firm does not enter-and therefore cannot deter the cooperative firm formation - and yet a coalition of consumers can be viable. There are two distinct regions of interest where the cooperative is viable while the PM firm is not. Areas $y$ and $z$ denote the region of the parameter space where the cooperative remains viable, while the PM firm is not: here $K>2 \bar{u} \equiv K^{m}$, and a PM firm cannot be profitable, regardless of whether or not it faces potential competition by followers. This parametric region is related to the too-few-by-one case of insufficient entry that arises in Mankiw and Whinston (1986). Area $x$ pertains specifically to the EMS framework analyzed in this paper and illustrates our main result. Here, $K<2 \bar{u} \equiv K^{m}$, and a PM leader who only needs to deter entry by other PM firms would find it profitable to be in the market. The prospect of competition by a cooperative firm, however, erodes the parametric region where the PM firm can profitably enter. As the coordination cost $G$ of the cooperative firm decrease, the level of fixed cost that the leader is able to sustain decreases. 
Main result. In the EMS framework, the need to deter the formation of cooperative firms, in addition to the entry of other PM firms, curtails the leader's ex post profit which affects the viability of entry. Thus no PM firm may find it desirable to enter the market, despite having a first-mover advantage. A cooperative firm may remain viable under the same production conditions, despite having to bear coordination costs that the PM firm does not have.

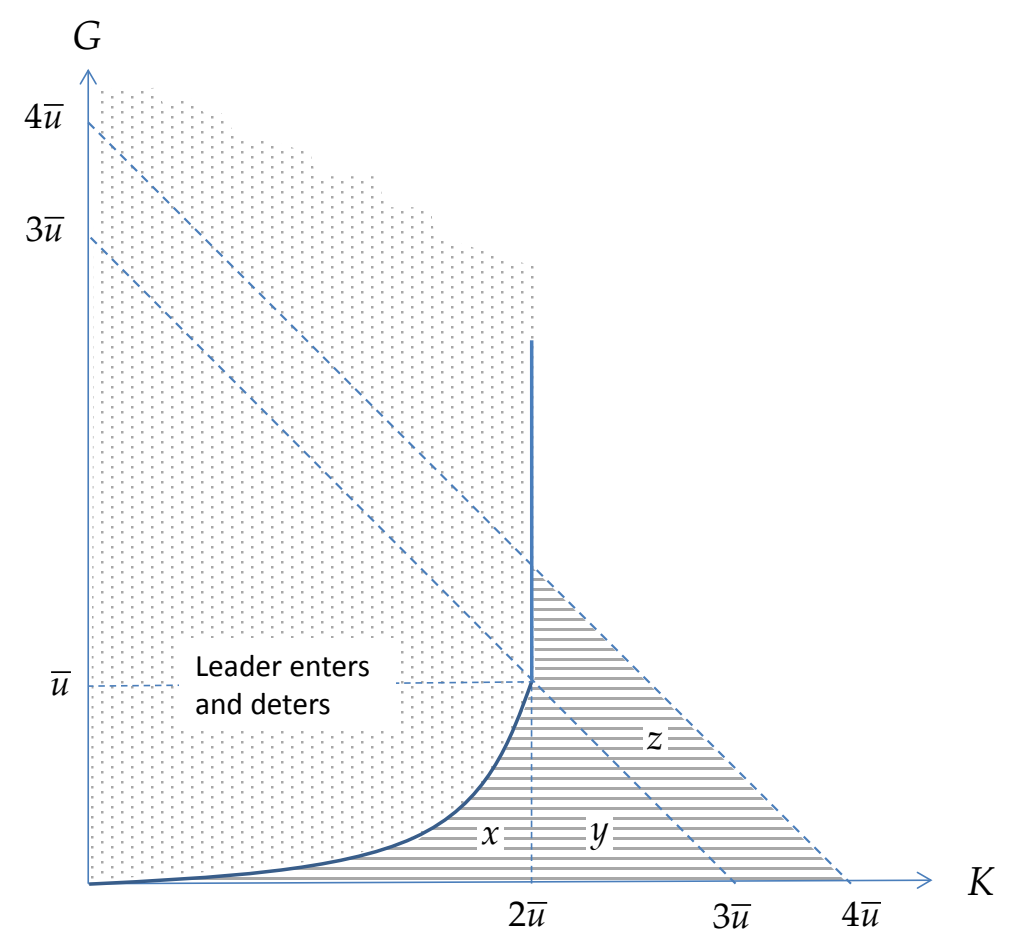

\section{Conclusion}

An incumbent PM monopolist has an incentive to practice entry deterrence strategies not just with respect to profit maximizing followers, but also to deter the formation of coalitions of consumers (Sexton and Sexton 1987, Innes and Sexton 1993). In this paper, rather than taking the position of the incumbent as given, we have followed the EMS literature and assumed that an entry cost applies to all active firms (although cooperative firms also have additional coordination costs). The analysis uncovers an appealing "raison d'etre" for cooperative firms. It defers to the view that a PM firm may be faster at exploiting a market opportunity, compared with a cooperative, and thereby gain a first-mover advantage. Such a leader may then be able to use entry deterrence strategies to preclude entry by other firms and/or cooperatives. But if the fixed setup cost is large enough, the leader may not find it profitable to enter the market. Perhaps more subtly, the foregoing analysis shows that the maximum fixed entry cost that the 
leader can endure is endogenous and depends on whether or not it faces the threat of entry by a cooperative. In such a setting, a cooperative firm may nonetheless be viable, despite being handicapped (relative to a PM firm) by the need to bear an additional coordination cost. This effect is particularly important in the case of nonconvexities because, as shown by Mankiw and Whinston (1996), the free-entry equilibrium number of PM firms may well be one or zero.

The role by which increasing returns to scale may explain the existence of cooperative firms has typically been cast somewhat differently: increasing returns lead to monopolies, and patrons may be induced to form cooperatives to avoid price exploitation (e.g., Hansmann, 2013). Our analysis points to an additional mechanism: fixed costs may be such that no PM firm finds it profitable to operate, especially when it faces the threat of entry by consumer coalitions. The cooperative organization might be the only viable solution in such an environment. 


\section{References}

Etro, F., 2006. “Aggressive Leaders.” The RAND Journal of Economics 37(1), 146-54

Etro, F., 2008. "Stackelberg Competition with Endogenous Entry." The Economic Journal 118, 1670-97.

Etro, F., 2013. “The Theory of Endogenous Market Structures.” Journal of Economic Surveys, doi: 10.1111/joes.12020.

Hansmann, H., 1994. The Ownership of Enterprise. New Haven, CT, Yale University Press.

Hansmann, H., 2013. "Firm Ownership and Organizational Form." Chapter in Robert Gibbons and John Roberts, editors, The Handbook of Organizational Economics.

Hart, O. and Moore, J., 1996. “The Governance of Exchanges: Members' Cooperatives versus Outside Ownership." Oxford Review of Economic Policy 12(4), 53-69.

Innes, R., and Sexton, R.J., 1993. "Customer coalitions, monopoly price discrimination and generic entry deterrence." European Economic Review 37, 1569-1597.

Mankiw, G.N. and M.D. Whinston, 1986. "Free Entry and Social Inefficiency." Rand Journal of Economics 17, 48-58.

Mikami, K., 2011. Enterprise Forms and Economic Efficiency: Capitalist, cooperative and government firms. Vol. 95. Routledge.

Sexton, R.J., and T.A. Sexton, 1987. "Cooperatives as entrants." The RAND Journal of Economics $18,581-595$. 